\title{
CMAJ gets interim editor amid governance shake-up
}

$\mathrm{D}$ r. Diane Kelsall, a long-time $C M A J$ deputy editor and editor of CMAJ Open, has been appointed interim editor of the $C M A J$ as part of the journal owner's restructuring and modernization plan.

On Feb. 29, the Canadian Medical Association (CMA) Board of Directors dismissed the journal's editor-inchief, Dr. John Fletcher, who had held the post for four years, and disbanded the Journal Oversight Committee, which was tasked with mediating between the journal and CMA on matters of editorial independence.

CMA President Dr. Cindy Forbes says the moves were part of a long-running overhaul of the whole organization. "We have been going through all of our products and services and looking at how we can best move into the future," she says. "We're looking for a new vision, new leadership. We're basically starting with a clean slate."

"We did appreciate Dr. Fletcher's contributions over the last eight years," she says.

CMA Past-President Dr. Chris Simpson will lead a task force charged with coming up with a new mission statement, goals and objectives for the journal. The task force includes Kelsall, Deputy Editor Dr. Kirsten Patrick, as well as Ann Michael, the president of the Society for Scholarly Publishing and a board member at NewCo, CMA's commercial subsidiary to which the journal was transferred in late 2014. The task force will consult with CMA members and experts in academic publishing, and deliver its preliminary report to the NewCo Board in October.

Despite disbanding the Journal Oversight Committee, the CMA remains committed to the principle of editorial independence, says Forbes. "Editorial independence is absolutely the cornerstone of any scholarly journal," she says. "We will do everything to uphold that principle."

The editor will now report directly to the CMA Board on matters of editorial independence, an arrangement that both Forbes and Simpson say made the Journal Oversight Committee "redundant." According to Simpson, the members of the oversight committee agreed with that assessment.

But Dr. John Wootton, chairman of the disbanded committee, denies that claim. "I don't think the committee ever expressed the opinion that access to the board by the editor, which actually existed already, made the committee redundant," he says.

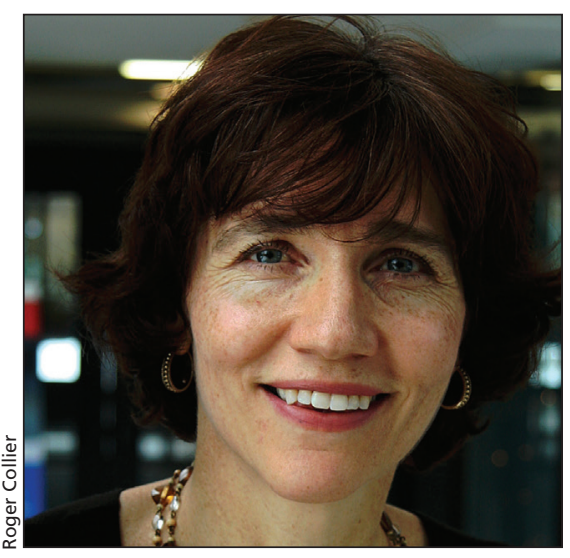

Interim Editor-in-Chief Dr. Diane Kelsall is part of a task force to determine the journal's direction.

Wootton says that the oversight committee had been concerned for some time about the relationship between the journal and NewCo. "Having CMAJ in the business arm could inevitably lead to tensions related to business matters rather than editorial issues," says Wootton.

It also goes against one of the main recommendations of a report by the committee charged with looking at the CMAJ's governance in 2006 in the wake of its last editorial crisis. At that time, the editor and senior deputy editor were fired after a news article was axed by the CMA. The committee, headed by Dick Pound, recommended that the journal be removed from the association's business arm and placed under the direct control of the CMA Board, a recommendation that the CMA heeded. "The creation of NewCo is a return to a situation that was not desirable," says Wootton.

The CMA has also ignored its own processes in unilaterally firing the editor, adds Wootton. The terms of reference of the Journal Oversight Committee require the CMA to consult with the committee before dismissing an editor.

The five external members of the oversight committee have written an open letter to the members of the CMA that strongly criticizes the decision to fire Fletcher and disband the committee. It describes the relationship between $C M A J$ and NewCo as a "dysfunctional forced marriage" and decries the "Orwellian logic" of claiming to support editorial independence while getting rid of the body tasked with preserving that independence.

Kelsall says she is concerned about the dissolution of the oversight committee, but reassured by the promise that she would have "unimpeded access" to the CMA Board. She says she is looking forward to the opportunity to do a complete overhaul of the journal's mission, structure and governance as part of the task force. "I'm excited to look at the best practices internationally, and see how we can innovate," she says.

"There were a lot of things already underway under John's [Fletcher's] steadfast and loyal leadership of the journal. I hope to continue [with those]."

Kelsall, a graduate of the University of Toronto, has been editing medical publications since 1997, including two years as editor of Canadian Family Physician, a peer-reviewed journal of the College of Family Physicians of Canada. She joined $C M A J$ as a deputy editor in 2008.

Simpson says one of the goals of the task force is to get Canadian medical researchers to think about $C M A J$ in the same terms as top-tier journals like The Lancet or JAMA. "Canadian researchers have always punched above their weight in the international scientific community, but they tend to send their best work to other journals," he says. "We have to build a sense of nationalism, an emotional connection to CMAJ."

The best way to build a strong publication is for the journal to adapt to the new ways that younger doctors want to receive information, says Forbes. "We want to be sure that the journal we have had for 105 years, we have for another 105 years." - Brian Owens, St. Stephens, NB

Brian Owens is an independent freelancer.

CMAJ 2016. DOI:10.1503/cmaj.109-5246 